\title{
Does a Halo Effect Exist in German Soccer? Results of an Empirical Study, Implications and Current Reference
}

\author{
Gerd Nufer \\ Reutlingen University, ESB Business School \\ Germany
}

\begin{abstract}
The halo effect is a cognitive bias known from social psychology. A halo effect occurs when a global impression or information about a salient characteristic shapes the evaluation of other characteristics. In a sports-related context, the halo effect has hardly been researched so far, although this could contribute significantly to understanding the thinking and behavior of sports fans. In this research paper, the following questions are investigated: Is there a halo effect in soccer? Does the sporting success or failure of a club outshine other sporting aspects? Does sporting success or failure possibly even distort fans' perception of nonsporting aspects? The research paper reflects the current state of halo research and presents the results of an empirical study in which fans of soccer clubs from the German Bundesliga were interviewed. The results of the analyses substantiate the distortion of the fans' perception with regard to a very diverse range of aspects that is triggered by the sporting success or failure of their favorite club.
\end{abstract}

\section{Introduction}

People take it for granted that their decisions and judgments are based on objective and logical thinking. In fact, however, human thinking is often unconsciously influenced by cognitive biases. Given the enormous amount of information available and the often limited time to take a decision, it is virtually impossible to carefully process and analyze each piece of information. Therefore, people tend to apply mental shortcuts, heuristics, to make decisions in a simplified and fast way. While many times a heuristic leads to accurate and effective conclusions, it is also highly susceptible to being influenced by cognitive biases. Cognitive biases are errors in thinking that result in biased decisions and judgments [1].

The halo effect is a cognitive bias known from social psychology that consists of inferring unknown characteristics of a person from known characteristics of that person. It occurs when a global impression or information about a salient characteristic shapes the evaluation of other characteristics [2]. A positive bias is called the "halo of a saint effect", a negative bias is called the "pitchfork effect" [3].

Studies of the halo effect have been conducted in a wide variety of research fields in business and management, especially in human resources or education, where objective and unbiased assessments are of central importance [4]. In contrast, the halo effect has been mentioned only marginally in the context of sports - and if so, then primarily with regard to individual athletes concerning the effects of the attractiveness of their appearance [5]. To the author's knowledge, studies analyzing the spillover effect of the athletic success of sports teams on other sporting and non-sporting aspects do not yet exist.

\section{Literature Review}

In 1907 Wells observed an effect according to which the first impression influences the evaluation of other characteristics [6]. Thorndike was the first to use the term "halo effect" in 1920. He observed the effect while studying the evaluations of army officers. He noticed that in many cases the ratings of completely different character traits of an officer correlated strongly with each other. From this, he concluded that these findings indicated an effect in which the persons rating were biased by the overall impression of a person - a halo effect [7]

\subsection{Characterization of the Halo Effect}

The word "halo" comes from the Greek word "halos". In astronomy, a halo is a ring of light surrounding the sun or moon [8]. Synonymous to the halo effect, the terms "blooming effect" or "spillover effect" are often used in the literature [9].

The halo effect follows the tendency of consistent evaluation. People try to create a consistent and coherent image of a person or a perceptual object. The halo effect allows them to keep explanations simple and coherent. The human brain wants to prevent inconsistencies because they prevent ease of thought and clarity of feeling. A halo effect makes it possible to reduce perceptions to a closed and coherent picture and to avoid cognitive dissonance. The starting point for the halo effect can be easily 
accessible features, such as appearance and physical attractiveness. Clothing, a facial expression, hair color, status, exceptional performance, or behavior can also lead to perceptual distortion [10].

The halo effect works in two directions: On the one hand, positive information results in more positively evaluated characteristics; on the other hand, negative information similarly leads to rather negative evaluations of characteristics [4]. Halo effects occur especially when the characteristics to be evaluated are not clear or difficult to determine, but can nevertheless be pronounced enough to have an influence on the evaluation of clearly identifiable characteristics [5].

\subsection{The Halo Effect in Business Management}

In case a company's sales, profits and share price increase, observers quickly conclude that it has a visionary CEO with a clever strategy and motivated employees, is particularly customer-oriented and has a good corporate culture. If, on the other hand, the company complains about falling sales and profits, people quickly draw the opposite conclusions - even though the real factors have remained unchanged. In other words, based on the success or failure of a company, conclusions are drawn about the strategy, the work of managers and employees and the corporate culture without any further information. It becomes clear that not only people, but also companies can be the subject of a halo effect [11].

Especially in marketing, the halo effect plays a significant role. "We sell lifestyle and give away motorcycles" is a statement of the motorcycle manufacturer Harley Davidson. This statement is confirmed by the fact that the Harley logo is the most frequently chosen motif for a tattoo in the USA. This example shows what makes a strong brand. The Harley Davidson brand obviously stands for much more than just their products motorcycles. It was recognized early on that the good reputation of a brand has a positive effect on the overall perception of quality ("branded products effect"). Because of a brand, consumers expect above all better product quality. After forming a general quality judgment, this in turn retrogradely influences the perception and assessment of individual properties [12].

A company can benefit from the halo effect especially when introducing new products. The image of an already established brand is transferred to a newly introduced product bearing the same brand name and motivates purchase [13].

The origin-related inference effect is also a halo effect. In case a consumer is uncertain about key product attributes, knowledge of the product's origin can lead to an irradiation of the country image to product attributes he is not aware of. Consequently, the image of the country of origin influences the assessment of product quality as well as the formation of attitudes towards the product to be evaluated [14].

In marketing communication, celebrities are often used as testimonials in order to benefit from a halo effect. The aim of such advertising measures is that consumers identify with the advertised brand on the basis of the testimonial's positive statements about the product and that a transfer of the testimonial's awareness and image to the product or brand is achieved. The testimonial ensures objectivity and credibility, and its good reputation or positive image is to be transferred [15].

\subsection{The Halo Effect in Sports Management}

Studies on the halo effect in the context of sports are extremely rare so far. Ströbel investigated the factors influencing brand valuation in sports and their impact on the financial brand value of club brands [16]. Although the halo effect is mentioned in the context of the brand concept, it is not explicitly linked to sports [16].

Preuß [17] also dealt with the importance and types of brands in sports and speaks of a halo effect. During the 2004 Olympic Games in Athens, spectators were asked about the image of the Olympic soccer tournament and that of the FIFA World Cup. The results-se showed that there were significant differences in the perception of the two tournaments on many attributes. The perceived attributes of the Olympic soccer tournament largely coincided with the perception of Olympic Games overall. The fact that spectators watched and rated the soccer games in the context of the Olympics obviously influenced their perceptions of the Olympic soccer tournament [17].

Mentions of the halo effect in sports can also be found when discussing the reputation of individual athletes. One example is the current coach of Liverpool FC, Jürgen Klopp. Previously, he coached Borussia Dortmund. In the days of Borussia's success, Klopp was seen as easy-going, clever, and people praised his clear way of playing soccer. When things were not going so well for his team in sporting terms in the 2014/15 Bundesliga season, he was accused that his team lacked a clear line, that the constantly changing tactical formations were a problem and that the successive departure from the successful system of previous years was the main reason for the crisis. Loch concluded that the different assessments by one and the same person could only gain plausibility through the criterion of sporting success as the only standard of assessment [18]. However, no empirical evidence or more detailed explanations were provided.

The fact that sporting success or failure is a salient feature and can have an influence on other areas of life is also illustrated by a study on domestic violence in England [19]. According to this study, 
clear results of the English national soccer team whether victory or defeat - increase the incidence of domestic violence. For example, after England's 4-1 loss to Germany in the 2010 World Cup in South Africa, the rate of domestic violence increased by $31.5 \%$ compared to the same day the previous year. The rate also increased during victories by the English national team. In contrast, the increase was only $1.9 \%$ for a draw, e.g., 1-1 against the United States, and only $0.1 \%$ for a draw against Algeria.

Hickman and Lawrence examined consumer responses to sports sponsors triggered due to halo effects. The study provides insights into and explanations for the thinking and behavior of sports fans [2]. A key finding is that sports fans who identify strongly with their team tend to transfer loyalty to their favorite club to its sponsors, which in turn results in positive attitudes toward the sponsor's brand [2].

The difference between sports fans and "normal" sports spectators is the personal value that fans attach to their favorite club. While the "normal" spectator is primarily interested in the sporting competition, fans regard being a fan as an integral part of their lives. They are much more emotionally involved and regularly think about and talk about their club in everyday life. "BIRGing" and "CORFing" are phenomena that are characteristic of sports fans and, at their core, are due to halo effects: BIRGing (= basking in reflected glory) means that people try to demonstrate a connection to successful others. In doing so, the person tries to portray themselves as successful by presenting a common characteristic of the successful and of themselves in public, i.e. fans like to express "we won" after a victory of their team [20]. CORFing (= cutting off reflected failure) means that people like to distance themselves from nonsuccessful others in their self-presentation. The reason for this is that people do not want to allow a negative image transfer to themselves, i.e. in case of defeat, the linguistic phrase "they lost" tends to be used [21]. It is typical that CORFing is rarely observed among diehard fans, but rather among fairweather fans.

\section{Empirical Study}

The following empirical study investigated the question of whether the sporting success or failure of a professional soccer club outshines other, sportsrelated and non-sports-related aspects and influences or distorts their perception in the eyes of its fans. The study aimed to find out whether or not a halo effect exists in soccer [22].

\subsection{Research Hypotheses}

The choice of hypotheses was based on the following considerations: A spillover effect from the sporting success of the favorite team to sport-related or club-internal aspects would be most comprehensible and to be expected. A potential ruboff of the sporting performance on non-sporting aspects in the private life of a fan is comparatively much less likely. The assumption that even the subjective feeling of happiness of a fan depends on the sporting success of the supported team is the boldest of the theses. Overall, this approach was intended to find out up to which areas the sporting success or failure of a soccer team has an effect on its fans.

Hypothesis 1: When a club is successful (not successful) in sports, fans perceive the club's management as positive (negative).

Hypothesis 2: When a club is successful (not successful) in sports, fans perceive non-sports aspects in their lives as positive (negative).

Hypothesis 3: The sporting success (failure) of the favorite club has an influence on a fan's subjective feeling of happiness.

\subsection{Research Design}

In the empirical study, fans of six selected clubs of the first German Bundesliga were interviewed: FC Bayern München, Borussia Mönchengladbach, Eintracht Frankfurt, 1. FC Köln, VfB Stuttgart and Hamburger SV. The survey was conducted in three waves: shortly before the start of the 2015/16 season (in August 2015), after the end of the first half of the season (in December 2015) and immediately after the end of the season (in May 2016). In addition, a control group of non-soccer enthusiasts was included in each wave. For data collection, the online panel of the professional provider Norstat Germany was used. Data were collected using Computer Assisted Web Interviewing (CAWI).

The survey was aimed at German-speaking soccer fans aged 14 and older who reside in Germany (nonsoccer enthusiasts served as the control group). The complete data set from the experimental and control groups comprised a total of 4,180 cases. The subjects were able to participate in all three waves. Considering oneself a fan of one of the six clubs studied was a prerequisite for being included in the experimental group. Furthermore, only responses from subjects who indicated a high or very high interest in soccer were considered for this purpose.

The collected data were analyzed using IBM SPSS and Microsoft Excel. The average age of respondents in the sample was just under 50 years. Around 65 percent men and 35 percent women took part in the survey.

\subsection{Research Results}

The six Bundesliga clubs considered were (as 
expected) located in very different regions of the Bundesliga table during and at the end of the 2015/16 season. At the end of the season, FC Bayern München won the German championship, the DFB Cup and reached the semifinals of the Champions League. Borussia Mönchengladbach finished fourth in the Bundesliga. 1.FC Köln and Hamburger SV finished ninth and tenth, respectively. Eintracht Frankfurt finished the season in 16th place and only secured its place in the league in the relegation round. VfB Stuttgart was relegated directly to the second Bundesliga after finishing 17th.

3.3.1. Analysis of sports-related Aspects. The first hypothesis considered sport-related factors. Is the perception of the management's work and other clubinternal aspects distorted by the team's sporting performance?

To this end, fans were asked about the following sport-related aspects regarding their favorite club:

- "The club's top management (president/CEO) is doing a good job."

- "The supervisory board does a good job."

- "The coach does a good job."

- "The marketing department is doing a good job."

- "The current jerseys are successful."

- "The club policy makes sense."

- "The manager/athletic director/sports director are doing a good job."

- "The club is making positive headlines."

- "All the people in charge of the club are pulling together."

The analyses conducted showed a clear dependence on sporting success for the selected sport-related aspects. This means that hypothesis 1 can be provisionally confirmed.

3.3.2. Analysis of non-sporting Aspects. The second hypothesis related to non-sporting factors of fans. It was investigated whether the perception of private aspects is influenced by the sporting performance of the favorite club.

To analyze this hypothesis, the fans' responses to the following non-sporting aspects were used:

- "The federal government is doing a good job."

- "I like my current job/school/study situation."

- "I enjoy my job/school/study."

- "My relationship/marriage is going well."

- "I am satisfied with my family situation."

- "I get along well with my friends."

- "Overall, I enjoy good health."

- "I have confidence in our society."

The findings of all the analyses carried out were unambiguous for all the non-sporting aspects examined: Here, too, there are dependencies on athletic success. Hypothesis 2 can therefore also be provisionally confirmed.
3.3.3. Subjective Feeling of Happiness. The third and final hypothesis examined whether a fan's subjective feeling of happiness (operationalized by the question "How happy do you feel overall?") is changed by the sporting performance of his favorite club.

The analyses showed a dependency here as well: The evaluation of a soccer fan's own happiness is significantly influenced by the sporting success of his favorite team. This means that hypothesis 3 can also be provisionally confirmed.

\section{Discussion}

The results of the analyses demonstrate the distortion of fans' perceptions with regard to a wide variety of aspects, triggered by the sporting success or failure of their favorite club: When the team is successful in sporting terms, both sport-related and non-sporting aspects are perceived more positively. Fans are even happier overall when their team performs well. When, on the other hand, their own team is not successful, other aspects are also viewed more negatively.

\subsection{Implications for Sports Management}

Clubs should be aware of the existence of the halo effect among their most loyal fans. It is in the interest of clubs to have both loyal and well-meaning fans. The research has shown that fans have a relatively unified opinion when it comes to evaluating sporting performance. They are able to assess their team's sporting performance well and are confirmed by the same assessment of other fans. In the event of failure, this awareness of being supposedly right or right can develop into a mood-lowering resentment toward the club. An open and honest relationship between the club or club management and fan groups can prevent this.

It is therefore advisable for clubs to manage their communication with fans with an awareness of their own current sporting performance. Skillfully applied, this can be used to optimize target figures: With a team currently being successful in sporting terms, an advertising campaign encouraging membership of the club would be most promising. The same applies to the promotion of merchandising articles. It can be assumed that if the team is successful in sports, the sale of merchandising articles is almost a foregone conclusion. However, if merchandising sales do not meet expectations due to sporting failure, this should be countered by targeted promotional activities.

Whenever a team fails in sporting terms over a long period, the wrong communication can drive a wedge between the team and the fans, the wellknown twelfth man. This can lead to unrest within the club, which often results in increased external pressure on the club management and ultimately 
culminates in the dismissal of the coach. However, adequate communication with the club's own fans can also lead to the club being strengthened from the outside by the fans, which promotes cohesion in times of crisis and continuity within the club ("no short-circuiting"). Accordingly, being aware of the reality of the halo effect and consistently aligning actions with it can, ideally, even influence future sporting success.

The strong bond between fans and their club can be evidenced by the halo effect. Ultimately, club and fans alike want nothing more than the team's sporting success. However, the motives behind this vary: the goal of a club is sporting success while ensuring the long-term profitability of the club. The existence of the halo effect shows that soccer fans also desire the sporting success of their favorite club because this has an impact on their private lives and their individual sense of happiness.

\subsection{Current Reference: "Die Mannschaft"}

In 2015, the German Soccer Association (DFB) was looking for a symbolic name for the national team that both German fans and the international media would perceive as a brand for the DFB eleven. From the DFB's point of view, the term "Die Mannschaft" (= the team) was a perfect fit for the then reigning world champions from 2014. In the following years, "Die Mannschaft" was taken up and activated by DFB sponsors. But despite permanent mention of the brand name, the term simply did not want to pass into the general vernacular of fans.

Especially after the debacle of the German team at the 2018 World Cup in Russia with its elimination after the preliminary round, the term "Die Mannschaft" is increasingly criticized by many fans (and subsequently also put to the test by the DFB itself). The term is interpreted as artificial and the DFB is accused of merely picking up and copying the ideas of other nations (e.g. "Seleção", "Azzurri" or "Les Bleus").

In the opinion of the author, the term "Die Mannschaft" is representative of the alleged overcommercialization of the DFB in recent years accompanied by excessive ticket prices, the exclusion of fans from training sessions, late kick-off times at friendly matches, etc. The original idea may not be as bad as its current image, but right now it has to stand in for a lot of other things that have gone wrong at the DFB in recent years. In other words, a halo effect can be observed here as well: Fans forgive world champions anything, sporting success outshining everything. But when the next World Cup is eliminated in the preliminary round as miserably as never before, they literally burst out laughing and criticizing things that already existed before.

\section{Conclusion}

While the pitchfork effect around "Die Mannschaft" is merely an assumption of the author based on plausibility considerations, the empirical study conducted can demonstrate a halo effect based on the sporting success or failure of selected Bundesliga clubs on the perception of sport-related aspects, non-sporting aspects and the subjective feeling of happiness on the part of fans at a statistically significant level. In other words: there is a halo effect in soccer:

In sports management and particularly in sports marketing, knowledge about how fans think, react and behave is essential to come up with appropriate and effective strategies. However, given the distinctive features of sports fans and their irrationality, it is hard to forecast how they react and how new strategies work out. Therefore, knowledge about halo effects and further research on halo effects in a sporting environment might help a great deal in better understanding the nature of sports fans.

\section{References}

[1] Tversky, A. and Kahneman, D. (1975). 'Judgment under uncertainty: Heuristics and biases', in D. Wendt and C. Vlek (Eds.), Utility, Probability, and Human Decision Making (pp. 141-162), Reidel, Dordrecht.

[2] Hickman, T. M. and Lawrence, K. E. (2010). 'The halo effect of goodwill sponsorship versus the pitchfork effect of supporting the enemy', Journal of Sponsorship 3(3), pp. 265-276.

[3] Kroeber-Riel, W. and Weinberg, P. (2003). Konsumentenverhalten ( $8^{\text {th }}$ ed.), Vahlen, München.

[4] Gräf, M. and Unkelbach, C. (2016). 'Halo Effects in Trait Assessment Depend on Information Valence Why Being Honest Makes You Industrious, but Lying Does Not Make You Lazy', Personality and Social Psychology Bulletin 42(3), pp. 290-310.

[5] Landy, D. and Sigall, H. (1974). 'Beauty is talent: Task evaluation as a function of the performer's physical attractiveness', Journal of Personality and Social Psychology 29(3), pp. 299-304.

[6] Wells, F. L., (1907). `A statistical study of literary merit', Archives of Psychology 1(7), pp. 1-30.

[7] Thorndike, E. L., (1920) 'Intelligence and its uses', Harper's Magazine 140, pp. 227-235.

[8] Online Etymology Dictionary, (2018). 'Halo'. http://www.etymonline.com/index.php?allowed_in_frame $=0 \&$ search $=$ halo\&searchmode $=$ none $\quad$ (Access Date: 28 August, 2018).

[9] von der Linde, B. and Schustereit, S. (2010). Personalauswahl. Schnell und sicher Top-Mitarbeiter 
finden, Haufe, Freiburg.

[10] Nawratil, G. and Rabaioli-Fischer, B. (2010). Sozialpsychologie leicht gemacht $\left(6^{\text {th }}\right.$ ed.), Kleist, Berlin.

[11] Rosenzweig, P. M. (2008). `Manager lassen sich über das Geheimnis des Erfolgs systematisch täuschen', GDI Impuls 11(2), pp. 58-67.

[12] Hätty, H. (2013). Der Markentransfer, Physica, Wiesbaden.

[13] Nufer, G. (2018). 'Was erfüllt sein muss, damit das Image einer Marke von Sport-Event-Marketing profitiert Bedingungen für das Zustandekommen eines Imagetransfers und mögliche Konsequenzen für die Praxis', Marketing Review St. Gallen 35(1), pp. 78-85.

[14] Han, C. (1989). 'Country Image: Halo or Summary Construct', Journal of Marketing Research 26(5), pp. 222229.

[15] Meffert, H., Burmann, C. and Kirchgeorg, M. (2008). Marketing. Grundlagen marktorientierter Unternehmensführung, Springer Gabler, Wiesbaden.

[16] Ströbel, T. (2012). Die Einflussfaktoren der Markenbewertung im Sport: Eine empirische Analyse der Zusammenhänge bei Klubmarken, Springer Gabler, Wiesbaden.

[17] Preuß, H. (2014). `Bedeutung und Arten von Marken im Sport', in H. Preuß, F. Huber, H. Schunk and T. Könecke (Eds.), Marken und Sport. Aktuelle Aspekte der Markenführung im Sport und mit Sport (pp. 3-27), Springer Gabler, Wiesbaden.

[18] Loch, T. (2015). 'Mit neuem Trainer zum Erfolg zurück?', http://www.diesportpsychologen.de/2015/01/07/ thorsten-loch-trainerwechsel-zurueck-zum-erfolg (Access Date: 7 June, 2015).

[19] Herrmann, S. (2012). 'Faustschläge nach dem Fußball', http://www.sueddeutsche.de/wissen/studiezuhaeuslicher-gewalt-faustschlaege-nach-dem-fussball1.1495653 (Access Date: 2 June, 2015).

[20] Cialdini, R. B., Borden, R. J., Thorne, A., Walker, M. R., Freeman, S. and Sloan, L. R. (1976). 'Basking in reflected glory: Three (football) field studies', Journal of Personality and Social Psychology 34(3), pp. 366-375.

[21] Snyder, C. R., Lassegard, M. and Ford, C. E. (1986). 'Distancing after group success and failure: Basking in reflected glory and cutting off reflected failure', Journal of Personality and Social Psychology 51(2), pp. 382-388.

[22] Nufer, Gerd / Mariot, David (2020). 'Der Halo-Effekt im Fußball', Sciamus - Sport und Management 10(4), Sonderausgabe zur 23. Jahrestagung des Arbeitskreises Sportökonomie 2019, pp. 144-161. 